\title{
The Importance of Empathy in Teaching: A Case Study in the Albanian School Environment
}

\author{
Prof. Assoc. Dr. Rregjina Gokaj \\ Email: rregjinagokaj@gmail.com
}

Prof. Assoc. Dr. Laureta Vavla

Email: lauretavavla@yahoo.com

Doi:10.5901/ajis.2016.v5n3s1p551

\begin{abstract}
This paper attempts to assess the empathy as a skill needed in teaching. It also will note the importance of future teachers' role in society. The application of new methods of teaching is gaining attention nowadays, but a special importance has still to be given to the social, psychological, and emotional relationship between the teacher and the student. The ability to move from one's psychological perspective, to apprehend, to understand the other is a crucial element needed in teaching, which is considered as the skill of empathy. This case study endeavors to measure the level of empathy of in-service teachers and if they regard it as an important element in teaching. Future teachers will also be taken into consideration in order to evaluate their ability of understanding not only perceptions, thoughts and beliefs of their future students but also their needs, feelings and emotions. Another important form of empathy, also called "compassionate empathy", takes our attention in this case study. It has to do with the ability to experience feelings that show care and emotional connection with other people's feelings, concerns, situations, or circumstances. This paper tries to identify the current level of empathy as a skill in some schools in Albania, but it also furnishes future teachers with information regarding empathy as a skill, its importance and tools needed in order to implement this skill for a more accurate teaching process. It also will help future teachers to build a friendlier environment and make their pupils feel at ease and help them become better citizens for our society.
\end{abstract}

Keywords: empathy, skill, future teachers, relationship, ability, feelings, concerns

\section{Teaching Process and Implied Teaching Skills}

Teaching is considered a sublime profession, which holds the infinite passion for the future. Teachers carry the responsibility of the next generation in all fields that is why teachers play a crucial role in our society. Because of this importance, teachers have always been searching for new forms, for new methods and creative ways of organizing their everyday job so that they could please not only themselves but also the students and their parents and families. In many aspects teachers succeeded in their profession although, the teaching process has changed with the passing of time. This change is considered radical in terms of new methods and new approaches, and the teaching process is seen as a dialogue that transmits knowledge from teacher to students. Teaching nowadays have taken a shift from traditional methods of desks in rows and students eager to listen and apprehend the "show-and-tell" teaching to new methods of considering students as critical thinkers, creative learners and active participators in the class. This urges the adaptation of innovative practices, which cooperate between a knowledgeable person that is a teacher, who cares about the motivation of a child to acquire knowledge. However, we should take care not to turn education into an act of depositing, as Paul Frere (2000) says, in which students are the depositories and the teacher the depositor ${ }^{1}$. All these perspectives seem difficult to achieve in societies with social and economical problems at a large scale, like ours, but we have to admit that some changes are occurring at least in more developed areas and big cities. The hardest and most important thing to change is the mentality of the teachers. Once achieved this, it will result for sure in the change and prosperity of the next generation, where teachers have everyday access to affect.

The teaching process also involves the parents and the community in a wider aspect. Parents help teachers in

${ }_{1}^{1}$ Freire, P.; Pedagogy of the oppressed. 2000, Publishing House Continuum, New York-London 
understanding the emotional needs, the social and cultural background of their children. In this way the teacher does not only mechanically repeat the same lesson for years in front of the class for all the students the same, but the teaching process takes another dimension in bringing the teacher closer to any of the student's needs and feelings that directly affect their motivation and self-esteem. This attention to students' qualities, as a fold of empathy, helps teachers identify gifted students towards bright ones.

\section{Empathy as a Set of Skills}

When we mentioned the change of mentality as the hardest thing to achieve, we first thought of ourselves as teachers. Our everyday job at the university with future teachers makes it less difficult to admit but more difficult to manage. Pedagogical obstacles are various and numerous, no matter how homogeneous a community is. The biggest obstacle is the origin of mistakes, ignorance and thoughtlessness. If a teacher explains the lesson at his best without taking into consideration all sorts of prejudices or empirical ideas, that students already have, according to John Dewey, ${ }^{2}$ then the teaching process becomes far more difficult to progress. Therefore, teachers should possess other skills, not only professional ones. The competence model that Council of Europe presents in their document, ${ }^{3}$ gives a list of skills teachers should have in order to raise democratic awareness and prepare better citizens for our society. The list includes:

a. autonomous learning skills as the skills required to pursue, organize and evaluate one's own learning in accordance with one's needs, in a self-directed manner, without being prompted by others;

b. analytical and critical thinking skills as the skills required to analyze, evaluate and make judgments about materials of any kind, (e.g. texts, arguments, interpretations, issues, events, experiences, etc.) in a systematic and logical manner;

c. skills of listening and observing as the skills required to notice and understand what is being said and how it is being said, and to notice and understand other people's non-verbal behavior;

d. Flexibility and adoptability as the skills required to regulate one's thoughts, feelings or behaviors so that one can respond effectively and appropriately to new contexts and situations;

e. Linguistic, communicative and plurilingual skills as the skills required to communicate effectively and appropriately with speakers who speak the same or another language, and to act as a mediator between speakers of different languages;

f. Co-operation skills as the skills needed to participate successfully with others in shared activities, tasks and ventures and to encourage others to co-operate so that group goals may be achieved;

g. Conflict - resolution skills as the skills required to address, manage and resolve conflicts in a peaceful way by guiding conflicting parties towards optimal solutions that are acceptable to all parties; and what we have considered as the key skill needed in the process of teaching,

h. Empathy as the set of skills required to understand and relate to other people's thoughts, beliefs and feelings, and to see the world from other people's perspectives.

Considering this list, we built a questionnaire to measure most of these skills of in-service and pre-service teachers with special attention to empathy. We do believe that empathy as a set of skills, which requires to put ourselves in the other's shoes, is the core element that teachers need to have and develop during their professional career. This entails inner ability of the teacher to be empathetic, firstly, and then some other benefits to build an atmosphere of empathy in the class. Effective teachers give students the opportunity to think about their personal interests and goals and use strategies to help them become self-motivated and responsible for their own learning. ${ }^{4}$ This is what we mainly teach in our Master programs for teachers and what teachers mostly admit already know, understand and implement during their classes. However, the persistent question of why effective teaching fails to have quick effective results is not only related to the slow development of generations in general, but we assume that good practice is still lacking in most of our schools. This led us to have this survey about the level of teaching competence in general and of empathy in particular.

\footnotetext{
2 Dewey, J., Moral Principles in Education, Houghton, 1909, Boston, USA

3 Council of Europe, Competences for Democratic Culture, 2016

${ }^{4}$ Anderman, E. M., \& Wolters, C. A. (2006). Goals, values, and affect: Influences on student motivation. In P. A. Alexander \& P. H. Winnie (Eds.), Handbook of educational psychology (2nd ed.). Mahwah, NJ: Erlbaum.
} 


\section{Questionnaire Findings}

A questionnaire is used in order to measure the knowledge of competences a teacher should have and to evaluate empathy of the teachers in the school environment. This questionnaire was distributed students being in-service and preservice teachers attending Master programs in Teaching at the University of Durrës and Elbasan, Albania. The number of the student - teachers involved in this questionnaire sums up to 458 , where $77 \%$ of them were females; $68 \%$ belong to $21-26$ age group, $24 \%$ to $26-40$ age group and the rest $8 \%$ to the age group over 40 years old. We also put them into four categories according to their working experience.

We introduced them with the objective, expectations, reason and structure of the questionnaire, which in the whole measures teacher competences. We introduced them our idea of evaluating empathy as a skill, its importance in our common profession and our keen interest to have progressive classes and motivated students. For new, inexperienced student-teachers we gave the clearest definition of the term: Empathy - the action of understanding, being aware of, being sensitive to, and vicariously experiencing the feelings, thoughts, and experience of another of either the past or present without having the feelings, thoughts, and experience fully communicated in an objectively explicit manner; also: the capacity for this. ${ }^{5}$

A set of questions was meant to assess empathy and passion of the teachers (see Annex 1). Question n. 1 "How do you do your job as a teacher" faces us with different results, where pre-service and less experienced ones showed much devotion to it (almost $62 \%$ of each category chose $a$. and b.); while Option d. (other) was left blank. We encountered interesting findings with question n. 3, "When you were first called "teacher", how did you feel like"; where less experienced teachers in majority answered with option a. This might reflect the lack of motivation to become teachers for passion but for the only reason to find a suitable job for them. In terms of emotional aspect, this finding needs special attention because it directly affects students in class. The most motivated ones seem to have been the category of the most experienced ones, the ones who in majority answered option $\mathrm{C}$. We are not sure if the result also holds some nostalgic feelings in itself or this category was really excited at its very first beginnings. The most interesting finding was with pre-service teachers, they almost answered option $\mathrm{d}$. (other) where they expressed their feelings when students called them "teacher" during their Active Practice Classes at schools.

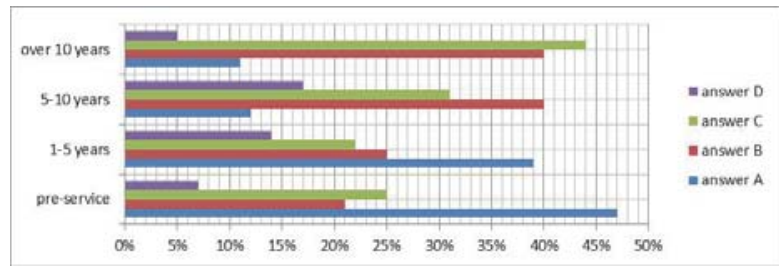

\section{Chart 2. First called "teacher"}

Another set of questions (6-10) was mainly focused in the teacher activities in class to increase, enhance and motivate student engagement during the lesson. In question n. 6 about effects on students' behavior, all categories agreed mostly on mutual understanding and trust as the main reason for a rooted and constructed dialogue between student and teacher. There were few options of answer a., because of the question was not very explicit. In option $d$. (other), some explained reason of option a., that is "tough behavior and strong discipline" affected student's behavior negatively. Most experienced teachers also chose option c., we think because this comes mostly from personal experience. This category is convinced that a strong reason of students' good behavior is a good explanation, which makes lesson more interesting and calls their attention. What we argue and do not fully comply with, is the dependence on the subject itself. This holds the thesis that Math teachers, for example, are very good at explaining Math but this does not affect the behavior of the students.

If we give a closer look at question n. 8, "What do you do to engage students in the learning process", we notice that answer a. got the maximum from category of over 10 years of experience. None of this same category gave any other option, that is d. we also notice that pre-service and young teachers have more or less the same values. The 
graphic values below are related to this question.

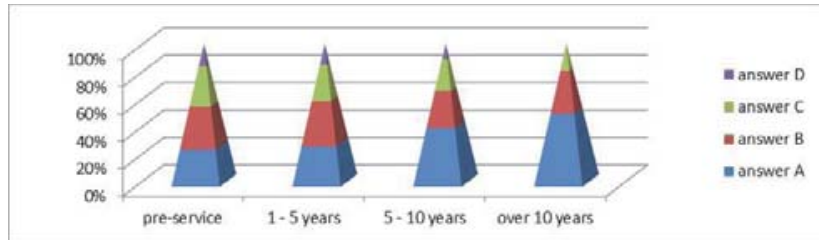

Chart 3. Ways to engage students

When we analyzed question n. 10, we found that almost all pre-service teachers answered option a., and the majority of the fourth category gave option b.; while motivation strategies had more or less the same values for the two mid categories of teachers. These two mid categories also had the same values for competitive situations, which makes us believe that the teachers of these categories have still some problems with the management of time for their subjects, that is why they do not risk organizing competitions or similar activities that are not included in their curricula or yearly program outlines. The most experienced teachers, on the other hand, know the value of competitiveness in class and are already used to managing it. This results in tracing gifted or bright students at given subjects, and our recommendation goes to the other categories not to stay stick to the yearly program outline, but try to have as much competitive spirit in class as possible. But on the other hand, motivation experts discourage competitiveness in the classroom, which is found to detract from students' intrinsic motivation to learn. ${ }^{6}$ Even though the questionnaire contained another similar question with more same logical options (see Appendix 1, Question n. 7), the results were almost the same. We made this on purpose so that we could compare later the results.

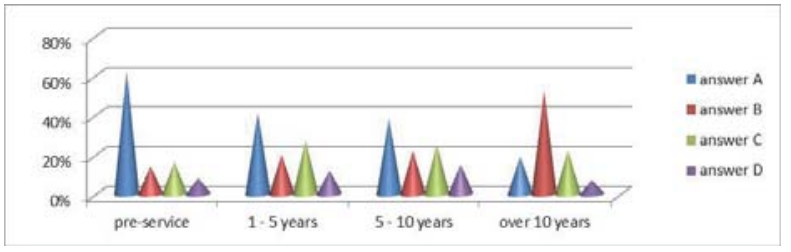

Chart 4. Ways for effective activation

Students were asked to answer some questions regarding the profession of the teacher, which they will carry out in the nearest future or that they are already experiencing. It was interesting to notice in the findings that most of the expectations were fully met by in-service teachers who already have a job experience between five to ten years. Thus, in questions regarding concrete situations, this category was straightforward and had clear cuts with the reality. The chart makes it clearer to us Question n. 14 of the questionnaire:

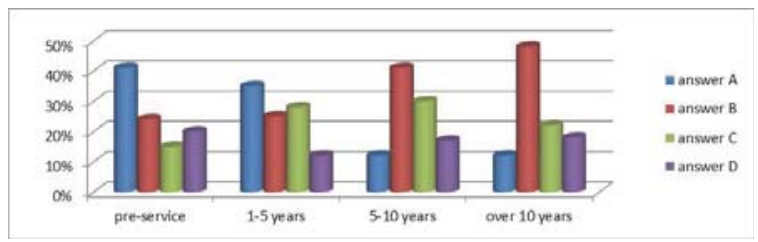

Chart 5. Students with special needs

${ }^{6}$ Wentzel, K. R. (1999). Social-motivational processes and interpersonal relationships: Implications for understanding motivation at school. Journal of Educational Psychology, 91(1), 76-97. 
Regarding question n. 15, we have more or less the same chart values between group 5-10 and over 10 years of experience. This explains the fact that in-service teachers know better how to deal with students with special needs, either because they have had such students in their classes or because they have taken further training modules about this issue. We can notice by the answers of pre-service or less experienced teachers that either they do not know how to deal with the case or they pay more attention than needed to this group leaving behind the rest of the class. In both cases, teachers of these two categories have to take into consideration the time limitations school programs permit.

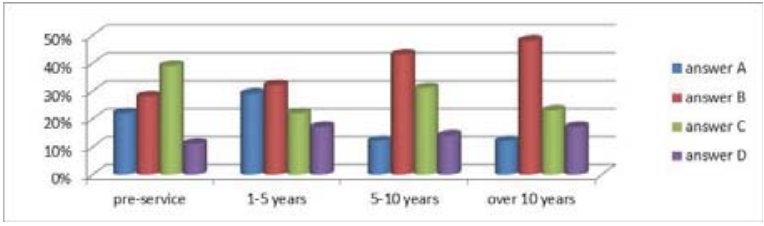

Chart 6. Measurement of teacher's reaction

The last chart below shows results to question $\mathrm{n}$. 17 where some alternatives of behavior are given and student-teachers have to choose one of them. The results give us quite an interesting tableau where the third category has more or less the same values for three alternatives and a note in the last alternative: it depends on the case. We can also notice how alternative d. You talk with him aside, shifts its values from pre-service teachers having high level, to 1-5 years the lowest level, then to 5-10 years higher, and the highest level is taken from the most experienced ones. This question is related to problem solving and conflict resolution and the way teachers might deal with it. From the answers, we can notice that preservice teachers are self confident theoritacally, but in the first years of experience where their friends are, we see that this method almost vanishes to flourish later in the third category and reaching the peak at the last category. In a typical conflict resolution scenario, teacher and students hold a class discussion about how a problem can be solved. To maximize its effectiveness, experts recommend teaching students communication skills, activating students' understandings of conflict resolutions by discussing examples (for instance, how countries solve their problems), and assigning a classroom area and time for the conflict resolution activity. ${ }^{7}$

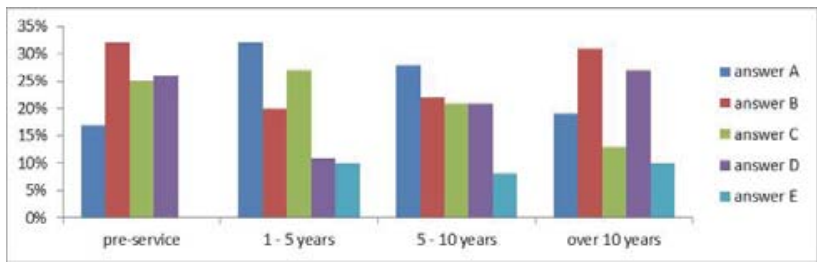

Chart 7. Teacher-student conflict solving

\section{Conclusion and recommendations}

This case study helped us be more attentive to the real needs our students have in order to develop themselves professionally and emotionally. We do believe that the findings of this questionnaire will be important for our studentteachers as well as for pre-service teachers. An accurate importance is given to questions that measure the level of compassionate empathy, although in an indirect way. The questions were built in a way where special attention took class management in many folders and perspectives, like creating a flourishing learning environment, where they can engage more in the class assignments. Effective classroom management focuses on prevention rather than intervention. Teachers can prevent management problems when they carefully plan instruction and demonstrate strong organization skills so that instructional time is maximized. It is critical for teachers to involve parents in their classroom management plan and collaborate with other teachers to identify obstacles to students' learning and find ways to overcome such

7 Jones, V., \& Jones, L.; Comprehensive classroom management (7th ed.). Boston: Allyn \& Bacon, (2004). 
obstacles. Misbehaviors range from minor and moderate rule and routine violations to serious offenses such as violence and aggression. Specifically, teachers should consider the following intervention progression: differential reinforcement, extinction, cueing, contingency contracting, token economies, and applied behavior analysis. Sociocognitive interventions focus on providing techniques that help students self-regulate their behavior, such as supporting students' goal setting, self-monitoring, selfinstruction, self-evaluation, and self-reinforcement. ${ }^{8}$ Teachers should take into consideration all these elements and consider them as prior needs for their students. Teachers should also encourage their students to make use of these techniques because they help them become better citizens, avoid hate speech and conflict behavior amid each other.

We judge that the recommendations of our case study are valuable not only for teachers but also for policy makers at local level or central one, as well as for curricula development in our universities.

\section{References}

Anderman, E. M., \& Wolters, C. A. (2006). Goals, values, and affect: Influences on student motivation. In P. A. Alexander \& P. H. Winnie (Eds.), Handbook of educational psychology (2nd ed.). Mahwah, NJ: Erlbaum.

Council of Europe, Competences for Democratic Culture, 2016

Definition offered by Webster-Merriam Dictionary: https://www.merriam-webster.com/dictionary/empathy

Dewey, J., Moral Principles in Education, Houghton, 1909, Boston, USA

Freire, P.; Pedagogy of the oppressed. 2000, Publishing House Continuum, New York-London

Jones, V., \& Jones, L.; Comprehensive classroom management (7th ed.). Boston: Allyn \& Bacon, (2004).

Moreno, R., Educational Psychology, John Wiley \& Sons, Inc., 2010.

Wentzel, K. R. (1999). Social-motivational processes and interpersonal relationships: Implications for understanding motivation at school. Journal of Educational Psychology, 91(1), 76-97.

Annex 1: Sample Questionnaire.

1. How do you do your job as a teacher:
a. With too much love
b. With devotion
c. A job like all the others
d. Other

2. How do you cultivate empathy in the class?
a. Working with communication strategies
b. Being collaborative with the students
c. Identify common values as well as differences among students
d. Other

3. When you were first called "teacher", how did you feel like:
a. As something normal
b. As an objective realized
c. As an incentive to keep on with this profession
d. Other

4. A teacher feels accomplished when:
a. Manages to put into work all his objectives
b. Lesson is fully acquired by the students
c. The class has high results
d. Other

5. What is your relation to your colleagues:
a. Social
b. Understandable
c. Distant
d. Other

6. Reasons that may better affect students' attitude are:
a. Tough behaviour and strong discipline
b. Mutual understanding and trust
c. Explanation at the best of the lesson
d. Other

${ }^{8}$ Moreno, R., Educational Psychology, John Wiley \& Sons, Inc., 2010, 444-5. 
7. One of the reasons that most encourages the student to learn is:
a. The affinity that you as a teacher show to him/her
b. Help you give during the class
c. Evaluation with positive words
d. Other

8. What can you do to engage students in the learning process:
a. Put assignments adoptable to the level of students
b. Assure to have an interactive method of teaching
c. Create jokes related to the topic
d. Other

9. How do you organize your class in order to have a higher level of learning by your students:
a. Putting in the first rows only active students
b. Dividing your students in groups
c. Putting in pairs active students to passive ones
d. Other

10. Which is the most effective way for each student to get activated in the class:
a. Rewarding positive behavior
b. Enrolling them in competitive situations
c. Motivation strategies for all students
d. Other

11. Which should be the teacher's role during the class:
a. Being empathetic
b. Being unrelenting
c. Being ambitious in achievements
d. Other

12. Which should be teacher responsibilities in the class:
a. Being sensible towards problems that arise in the class
b. Not ignoring students' problems
c. Being concerned about each student's personality
d. Other

13. If you have students with outside problems, how do you react:
a. You ask the help of the school psychologist
b. You talk with the student privately
c. You help him/her within your possibilities
d. Other

14. If you have a students with special needs, how do you react:
a. You let him understand as much as he can
b. You include him/her in the group works in class
c. You give him more attention than you give to others
d. Other

15. If you are put to a difficult question, what do you do:
a. You accept you don't know the answer
b. You tell them you'll get info about it
c. You pretend you didn't hear that
d. You pay no attention at all
e. Other

16. If a student interrupts your teaching, what do you do:
a. You pay no attention and keep on teaching
b. You get his attention by blaming
c. You punish him by sending him out
d. Other

17. If you ever got into a conflict with a student, what is your reaction:
a. Abrupt
b. You try to keep calm
c. You notify his parents
d. You talk with him aside
e. Other

18. When student's answer is not the right one, what do you do:
a. You oppose it
b. You approve it
c. You oppose it by completing
d. Other 